DOI: 10.20472/IAC.2017.029.001

\author{
AKIHIRO ABE \\ Iwate Prefectural University, Japan
}

\title{
INFORMATION SERVICE FOR A GEOPARK INCLUDING EARTHQUAKE STRUCTURAL REMNANTS: AN ACTION RESEARCH APPROACH
}

\begin{abstract}
:
The Great East Japan Earthquake that struck on March 11, 2011 caused massive damage centered on the Tohoku region of Japan, and disaster recovery efforts continue in the area even today. The region is moving forward with the development and use of the Sanriku Geopark, which uses earthquake structural remnants as part of its tourism assets, and it aims to have the facility added to the Global Geoparks Network. The goal of this study is to contribute to both tourism recovery and preventing the loss of the lessons of the earthquake by elucidating the ideal form of effective information services for a geopark that includes earthquake structural remnants. Since the Great East Japan Earthquake is a negative experience, there was a need to move forward with design of information services while ascertaining the intentions of stakeholders in the local community, who consist of a diverse range of subjects. Accordingly, we proceeded with service design based on three main policies: First, we employed the analytical methods of the Business Analysis Body of Knowledge (BABOK $\left.{ }^{\circledR}\right)$ to conduct stakeholder analysis of the diverse range of stakeholders involved in preservation and use of earthquake remnants. Second, we adopted a human-centered design (HCD) process to enable participatory design, in light of the need to create new services grounded in the intentions of local residents as well as the needs of visitors. Third, we introduced the stakeholder management perspective of the Project Management Body of Knowledge (PMBOK $®$ ) in an attempt at integrated process management from stakeholder analysis through the derivation of services through the HCD process. We believe that through this approach we were able to identify the ideal forms of information service concepts and provision systems through ICT to contribute to both prevention of loss of the lessons of the earthquake and promotion of new tourism programs, while obtaining the understanding of local residents and others who were the parties actually affected by the earthquake. The knowledge obtained through this study also is likely to be useful in design of information services for other open-air museums for which diverse stakeholders support management.
\end{abstract}

\section{Keywords:}

ICT Service Design, Open-air Museum Management, Action Research 


\section{Introduction}

The Great East Japan Earthquake that struck on March 11, 2011 caused massive damage centered on the Tohoku region of Japan. Although efforts are beginning to help tourism to recover in the affected areas through disaster training and preservation and use of earthquake structural remnants, the number of tourists visiting the Sanriku area of Iwate Prefecture, which suffered particularly severe damage, remains at about $80 \%$ of its level from before the disaster, and this remains a pressing issue. The Sanriku region is moving forward with the development of the Sanriku Geopark, which aims to preserve precious natural heritage while also considering earthquake structural remnants to be part of its assets, and the project aims to have the facility added to the Global Geoparks Network. This is expected to help create a new kind of tourism by adding to traditional sightseeing an element of geotourism, incorporating scientific perspectives from geology and geography. However, the Great East Japan Earthquake was a negative experience. For this reason, there is a need to proceed with care while ascertaining the intentions of stakeholders in the local community, who consist of a diverse range of subjects, with regard to utilizing earthquake structural remnants in through tourism and other activities.

Numerous studies have been published on application of stakeholder analysis to information systems and services for large-scale systems of corporations, government agencies, etc., including studies on stakeholder management methods in projects and those on identification of diverse stakeholders and consensus building. On the other hand, a look at studies on application of stakeholder analysis to local communities shows that most studies have addressed the topic of building consensus among stakeholders with regard to local issues such as environmental problems or community development. We were unable to identify any published reports of knowledge regarding adoption of information systems and services.

The goal of this study is to contribute to both tourism recovery and preventing the loss of the lessons of the earthquake by elucidating the ideal form of effective information services for a geopark that includes earthquake structural remnants, through action research. Since this study is oriented strongly toward practical research to contribute to solutions to problems in the field, it employs a form of action research in which researchers obtain knowledge on solutions to problems in the local areas while intervening in activities conducted there. First, this paper will describe the research scheme. Then, it will describe the process strategy of design of information services implemented through action research. Lastly, it will consider an overview of the new services identified and knowledge obtained through their design. 


\section{Research Scheme \\ Features of the Subject Field}

The goal is for the Sanriku Geopark, which was added to the Japanese Geoparks Network in September 2013, to be added to the Global Geoparks Network in a few years (SANRIKU GEOPARK, 2014). Covering an authorized scope of approximately $300 \mathrm{~km}$ of coastline and including 48 registered geosites, it is the largest geopark in Japan. Its geosites include not only sites of scenic beauty such as the Jodogahama rias shoreline but also earthquake structural remnants.

Other tourism resources created after the earthquake include disaster recovery tourism and the long Michinoku Shiokaze Trail. Recovery tourism aims to establish businesses centered on study tour programs including guided tours and tours of earthquake structural remnants for visitors to the region on school educational trips and corporate training trips, based on the themes of training and learning about disaster prevention. The Miyako area was the first to begin such efforts, and from their start in spring 2012 through now they have welcomed more than 97,000 visitors. These efforts are highly significant not only as a means of promoting tourism but also because they help prevent the loss of the lessons of the earthquake. The Michinoku Shiokaze Trail is a national long-distance national hiking trail connecting vestiges of the earthquake along its north-south route.

It is said that the key to promoting tourism in Sanriku is the use of these three tourism resources created after the quake. This study considered the entire region as an open-air museum, including not only the assets making up the geopark but also recovery tourism, the long trail, and preexisting tourism resources. Also, in light of the geographically broad authorized scope of the geopark and the state of its recovery tourism efforts, the Miyako area was chosen as the field area for this study.

The expression "open-air museum" refers to a museum in which architecture and exhibited items are gathered, preserved, and utilized outdoors. The objects of exhibition can consist of cultural assets, natural assets, or both. In this article, "open-air museum" does not refer only to traditional museums where items are preserved and displayed by a specialist such as a curator. It also refers to new formats, such as the ecomuseums created in France, where the region's residents actively participate in maintenance and management. Open-air museums are rarely located only outdoors and are generally accompanied by a central indoor exhibition facility that houses informational functions critical to understanding the exhibits.

\section{Action Research}

Since this study is oriented strongly toward practical research to contribute to solutions to problems in the field, it employs a form of action research in which researchers obtain knowledge on solutions to problems in the local areas while intervening in activities conducted there. First proposed by the psychologist Kurt Lewin, action research (LEWIN, 1946) has evolved through its use in a wide range of interdisciplinary research activities 
involving social practice. Published reports of action research intended to collect and utilize knowledge obtained through the processes of development, assessment, and adoption of information systems first began to appear during the 1990s and have increased in number steadily since the 2000s.

Our laboratory conducts education and research aiming to create solutions and new services through information systems for community issues, through integrated advancement of practical research through education and action research based on a problem-based learning/project-based learning (PBL) approach. Through now, we have carried out education and research on tour support systems for a number of open-air museums in Iwate Prefecture (ABE, 2016). While it is difficult for students involved as part of PBL activities to participate in multiple cases during their time as students, faculty members are able to intervene in and compare multiple subject fields in continuous and cross-sectional ways by guiding their students. Put another way, they should be able to compare and contrast multiple sites and to compare and contrast the same sites at different points in time.

\section{Information Service Design Practice}

We decided to set up three major policies and then proceed with design of information services for a geopark including earthquake structural remnants while ascertaining the intentions of stakeholders in the local community.

\section{Policy 1: Stakeholder Analysis through BABOK®}

We employed the analytical methods of the Business Analysis Body of Knowledge (BABOK®) (IIBA, 2013) to conduct stakeholder analysis of the diverse range of stakeholders involved in preservation and use of earthquake remnants. Identifying as the main stakeholders the expected system users of tourists, content providers (government tourism staff, tourism associations, and tourism businesses), and parties involved in disaster recovery (government disaster-prevention staff, nonprofits, and recovery volunteers), we assigned high priorities to local residents, who are the parties involved directly in the disaster, and tourists, who are the subjects intended to be attracted to the facilities. Based primarily on results of interviews, we conducted analysis using materials including rich pictures summarizing stakeholders' values and relationships, grid diagrams of power and interest for considering how stakeholders are related, engagement assessment matrices covering stakeholders' engagement in the project, and onion diagrams identifying the scopes of impacts during service operation.

\section{Policy 2: Participative Information Service Design through HCD processes}

We adopted the human-centered design (HCD) process of ISO9241-210 (ISO 2010) to enable participatory design (MULLER et al., 1993), in light of the need to create new services grounded in the intentions of local residents and government as well as the needs of visitors. The steps of implementing this HCD process are described below. 
Understanding and clarification of the state of use (Step 1): Through methods targeting stakeholders including workshops, interviews, and behavioral observation, ascertaining the situations and properties of use of the information services.

Clarification of users' requirements (Step 2): Sorting out visitors' requirements for information provision, based in part on the intentions of tourism agencies on the service operation side.

Development of solutions through design (Step 3): Development of prototypes, giving practical form to images of realization, and identifying solutions to technical issues.

Assessment (Step 4): Having stakeholders asses prototypes and repeating improvements by returning to any of the steps from Step 1 through Step 3 as appropriate until systems and services are confirmed to be useful for the solutions intended initially.

\section{Policy 3: Stakeholder Management through PMBOK®}

We introduced the stakeholder management perspective of the Project Management Body of Knowledge (PMBOK®) (PMI, 2013) for loose management of the HCD process. Since stakeholders' intentions could change depending on the state of recovery, there is a need to reflect their intentions while communicating with individual stakeholders in light of their own positions. Accordingly, we employed communication strategies corresponding to the position of each stakeholder identified in the power-interest grid diagrams. For example, tourism associations are stakeholders with high levels of interest and authority, and we strived to maintain close communication to enable reliable support for system development and operation. In addition, ordinary tourists are stakeholders with high levels of interest but low levels of authority, and for them we developed systems capable of publishing information on the state of efforts and collecting opinions via social networking and other means.

\section{Findings and Discussion}

As an example of a system for realizing information services for a geopark that includes earthquake structural remnants, we attempted to develop a system for support of tour itineraries (YOROZU et al., 2016). This system uses a CMS platform that makes it possible to manage content in accordance with the properties of various tourist sites (OGIHARA et al., 2012), to distribute it via the Web, and to develop applications efficiently. It contains information on 56 sites in total, consisting of geosites in the Miyako area, earthquake structural remnant spots, other key tourist spots, and restaurants and bars. In addition to seven model itineraries prepared in advance, it also enables users to prepare their own original itineraries. While users can view photographs of earthquake structural remnants from the time of the quake and after recovery, in consideration of the fact that some people would prefer not to view earthquake-related information the system is set up so that such detailed information is shown only those who desire it. As 
requested by tourists, it also makes it possible to check safety information on evacuation sites for use in the event of an emergency.

After twice evaluating prototypes of this system, at present it is being used on a trial basis for the general public on a tourism association website (YOROZU et al., 2017). While from the results of operation through now the system has been assessed as being useful for encouraging study tours and promoting tour itineraries to view earthquake structural remnants, topics for consideration such as the following have become clear.

First, an open-air museum involves moving around a vast outdoor site. For this reason, there is a need to provide not only descriptions of sightseeing spots but also information on routes and means of transportation connecting them as well as general information providing an overview of the museum as a whole, from different levels. For example, while it had been expected that visitors will use the long trail as a route connecting geosites, since no policy on its use has yet been established in the Miyako area the decision was made not to incorporate such information into the prototype system at this time.

Second, consideration should be given to display of information in the tour support system concerning the relationship between core facilities (indoor exhibits) and outdoor exhibits, a distinctive property of an open-air museum. This too remains a topic for future consideration since indoor guidance facilities still are in the process of being developed in the Miyako area.

Third, while gamification features such as stamp rallies to encourage visits to multiple geosites and augmented reality (AR) features such as simulated earthquake experiences might be effective ways of supporting tours of an open-air museum, since when using mobile devices outdoors screen visibility can decrease in sunlight on a clear day there is a need for provision of audio information either simultaneously or as an alternative to onscreen information. Also, if visitors focus solely on the screens of their devices they might miss out on the enjoyment of natural beauty and strolling outdoors that are the true attractions of an open-air museum. For this reason, in the future we plan to design services with consideration for balance between time spent operating the device and viewing the site.

Fourth, another conceivable approach is that of linkage with a digital archive specializing in earthquake information. Enhancing the content in this way could enable development of information services for use not only by visitors but also by local residents in efforts to learn from the disaster and pass along information. One possible method would be that of continuing to bring together resident-participatory content so that local residents' disasterprevention awareness will remain heightened.

It goes without saying that in aiming to promote tourism and help the number of people coming to the area to recover, instead of simply relying on earthquake recovery aspects alone it is essential proactively to communicate traditional tourism information (i.e., up-to- 
date information on popular tourist spots, food, and events). For this reason, enhancement of efforts by local tourism associations and tourism businesses to communicate information via social networking and other means probably is an important prerequisite.

\section{Conclusion}

In this study we were able to obtain a degree of knowledge on the ideal forms of information service concepts and provision systems to contribute to both tourism promotion and prevention of loss of the lessons of the earthquake, through action research. However, a number of issues remain for future study, such as support for promotion of tour itineraries as an open-air museum utilizing the long trail, information linkage with the core facilities of internal exhibits, utilization of earthquake archives, and enhancement of tourist information services. We plan to address the following two points in the future. First, we will strive to improve the information services through a sort of virtuous circle resulting from continued action research on the above topics. Also, it is conceivable that the design process employed in this study could be applicable to a wide range of information service designs for open-air museums whose operations are supported by diverse stakeholders in the community. We would like to proceed with efforts to apply the knowledge obtained through this study to a wide range of fields as an information-service design methodology for open-air museums.

\section{Acknowledgement}

This work was supported by JSPS KAKENHI Grant Number 26360070.

\section{References}

ABE, A. (2016). Case Study on Visit Characteristics of Open-air Museum Information Service Users, in Proc. 23th IISES International Academic conference, pp.1-7.

IIBA (2013). A Guide to the Business Analysis Body of Knowledge: Version 2.0, Lightning Source Inc.

ISO 9241-210 (2010). Ergonomics of Human-System Interaction - Human-Centred Design for Interactive Systems.

LEWIN, K. (1946). Action Research and Minority Problems, Journal of Social Issues, Vol.2, No.4, pp.34-46.

MULLER, M. J., WILDMAN, D. M. and WHITE, E. A. (1993) Participatory Design, Communication of the ACM, Vol.36, No.4, pp.24-28.

OGIHARA, Y., KAWAMOTO, K., ICHIKAWA, H., KUBOTA, S. and ABE., A. (2012) Development of Content Management System for Tourist Information Distribution, IPSJ SIG Technical Reports, Vol.2012-IS122, No.1, pp.1-8.

PMI (2013). A Guide to the Project Management Body of Knowledge: PMBOK Guide, Fifth edition, Project Management Inst. 
SANRIKU GEOPARK. (2014). Japanese Geopark Certified Sanriku Geopark Official Website, Available at http://sanrikugeo.com/ [Accessed 17 Apr. 2017].

YOROZU, N., ABE, A., ICHIKAWA, H. and TOMIZAWA, H. (2016). Analysis and Development of Tourist Information System Considering Earthquake Disaster Information, IPSJ SIG Technical Reports, Vol.2016-IS-138, No.4, pp.1-8.

YOROZU, N., ABE, A., ICHIKAWA, H. and TOMIZAWA, H. (2017). Development and Evaluation of Tourist Information System Considering Earthquake Disaster Information, Proc.78th National Convention of IPSJ, 1 ZE-03. 